\title{
Identifying societal challenges in flood early warning systems
}

\author{
Duminda Perera $^{\text {a,b,c,*, Jetal Agnihotri }}{ }^{\text {a }}$, Ousmane Seidou ${ }^{a, b}$, Riyanti Djalante ${ }^{\mathrm{d}}$ \\ ${ }^{a}$ United Nations University Institute for Water, Health and Environment (UNU-INWEH), Hamilton, ON, Canada \\ ${ }^{\mathrm{b}}$ University of Ottawa, Ottawa, ON, Canada \\ ${ }^{\mathrm{c}}$ McMaster University, Hamilton, ON, Canada \\ ${ }^{\mathrm{d}}$ United Nations University Institute for the Advanced Study of Sustainability (UNU-IAS), Tokyo, Japan
}

\section{A R T I C L E I N F O}

\section{Keywords:}

Civil society organizations (CSOs)

Disaster risk reduction (DRR)

Flood early warning systems (FEWS)

Flood risk

Preparedness

Response

\begin{abstract}
A B S T R A C T
Flood Early Warning Systems (FEWS) are implemented in many parts of the world, but early warnings do not always translate into an emergency response from all individuals at risk. This article examines challenges such as warning communication and community response capabilities. Literature review, global online survey results, and experiential knowledge helped identify cross-cutting issues such as failure to use participatory approaches involving communities and addressing their concerns in warning, insufficient preparedness and response levels of FEWS, inadequate translation of disaster risk reduction (DRR) policies into action at the community level, lack of DRR knowledge and practices among key stakeholders, insufficient gender and social inclusion in all stages of FEWS, gaps in institutional communication and collaboration, and, finally, technical and financial constraints. The paper also discusses the contribution of Civil Society Organizations (CSOs) in addressing the identified challenges and eventually strengthening FEWS locally. CSOs were found to act positively at local level challenges and significantly contribute to addressing them through tailored solutions to community concerns. Such solutions include DRR awareness campaigns to educate the communities and key officials; enhanced communication between vulnerable communities and local authorities; transforming reactive community response that relied on government officials to a risk-informed and self-prepared community response; gender inclusion and diversity in various stages of FEWS; and advocacy campaigns to build resilience to disasters. Eventually, policy-based recommendations that can help to root out the challenges discussed in this study are presented.
\end{abstract}

\section{Introduction}

Floods accounted for over half of the total water-related disasters that occurred from 2001 to 2018 and were responsible for about 94,000 casualties and USD $\sim 504$ billion financial losses globally [1]. The Sendai Framework for Disaster Risk Reduction 2015-2030 has seven targets and four priorities for action. Target 7 of the framework focuses explicitly on "substantially increasing the availability of and access to multi-hazard early warning systems and disaster risk information and assessments to people." UNDRR [2] states that effective "end-to-end" and "people-centered" early warning system comprises four interrelated components: (1) disaster risk knowledge based on the systematic collection of data and disaster risk assessments; (2) detection, monitoring, analysis and forecasting of the hazards and possible consequences; (3) dissemination and communication, by an official source, of authoritative, timely, accurate and actionable warnings and associated information on likelihood and impact; and (4) preparedness at all levels to respond to the warnings received.

The authors conducted a survey of operational Flood Early Warning Systems (FEWS) in 2019. The analysis of survey responses suggested that FEWS number nearly doubled since 2000 [9]. Fig. 1 shows a gradually declining trendline for flood disasters and mortalities while a significant decline for the individuals affected by floods globally during the 2000-2018 period. The declining trend in the affected population, mortality and flood occurrence may be explained by the continuous efforts in flood mitigation and risk reduction strategies, including FEWS. However, financial losses incurred due to floods are on the rise over the same period. This is likely because FEWS may not affect economic losses directly as non-transferrable asset losses can still occur.

The ability of FEWS to mitigate flood risks and impacts on communities is widely acknowledged [3-8]. It was found in Ref. [9] that developing and developed countries often have similarly well-established flood forecasting and early warning components in their FEWS. In contrast, communication and response components are

\footnotetext{
* Corresponding author. United Nations University Institute for Water, Health and Environment (UNU-INWEH), Hamilton, ON, Canada.

E-mail address: duminda.perera@unu.edu (D. Perera).
} 


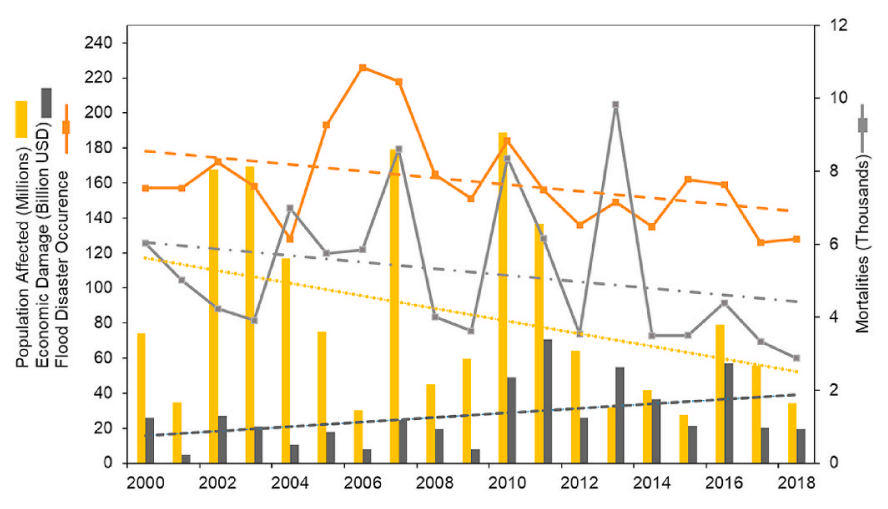

Fig. 1. Trends in flood occurrence, casualties, people affected, and economic losses incurred due to flood disasters globally (Data Source: EM-DAT).

less developed. Moreover, casualties and economic losses are found to be higher in developing nations, suggesting that warning communication and ability of the community to timely respond to the flood alerts are those parts of FEWS that need to be strengthened in the developing world. This issue is present in the developed world as well, though [42, 43]. It is well-documented that the production of technically sound early warnings is meaningless if it does not translate into emergency response action. Failure to respond to flood alerts can result from misunderstanding of the warnings and an inefficient of coordination between stakeholders and actors at all levels of FEWS. It may also be due to a lack of resources, knowledge, or contingency plans [3,4,7,10-14]. Yet, most of the FEWS-related literature either focus on purely technical aspects of FEWS (i.e., risk knowledge and flood forecasting components) [15-18] or describe the entire FEWS with limited attention to communication and preparedness components $[4,19,20]$.

Accordingly, the focus and objectives of this paper are to:

1. Identify societal challenges in flood warning communication, preparedness to respond, and response capabilities

2. Discuss the role of Civil Society Organizations (CSOs) in addressing the gaps outlined above, particularly at the community level

3. Formulate policy recommendations that may help strengthen governance and institutional capacity at all levels

\section{Flood early warning systems}

Fig. 2 describes the typical components of a FEWS, where risk assessment forms the foundation of the system and includes risk mapping and assessing the population, land-use, and assets. It is followed by data collection (generally, precipitation and temperature), to force a hydrologic model that simulates river discharges. A hydraulic/hydrodynamic modeling would then be used to predict water levels and floodplain extent. If a pre-set threshold is exceeded or is likely to be exceeded in the near future, a flood warning is issued. The warning information is then disseminated through various media to the communities at risk, and potential flood victims would be required to take appropriate action, such as evacuating to higher safe grounds. In some cases, an intermediate flood forecasting system, which involves real- time upstream river monitoring and prediction of downstream floods based on simple regression analysis or past experiences, can be as effective as a sophisticated flood forecasting method [48,50]. Risk knowledge, monitoring, and flood forecasting elements of the FEWS are generally carried out by a formal technical institution equivalent to Flood Forecasting Centres (FFCs). Sometimes, flood forecasting responsibility lies with different institutions such as the department of agriculture, conservation authorities, or the national hydrological service. There have been many technological advances in the production of timely and accurate flood forecasts thanks to investments in data collection, monitoring, training, and promotion of new technologies, especially in the developing world [9]. Yet, the three non-technical components of FEWS (Fig. 2) have not received similar attention [9]. These components involve collaboration between a variety of stakeholders, including disaster management committees, local authorities, CSOs, and communities at risk. This collaboration remains limited because of a range of barriers. The lack of cooperation, in turn, is a frequently invoked reason for the failure of the entire FEWS [3,4,11]. These factors tend to receive less attention from FEWS developers and operators who are generally from technical backgrounds such as engineering and atmospheric sciences. Advances in the non-technical components of FEWS are not as decisive as in the technical components. This is a serious problem for the 'end-to-end' effectiveness of FEWS, which's fundamental goal is to prevent human, property, and economic losses. Some examples of low-income countries such as in Bangladesh and Cuba exist where end-to-end FEWS have been effective [43,44]. Even a technically sound flood alert is ineffective if the intended recipient does not receive the warnings, does not understand it, or is not able to take actions promptly. Gaps in non-technical components of FEWS are identified in this paper through a literature survey and experiential knowledge. The gaps are then categorized into gaps in dissemination and communication, preparedness, and response capabilities, and discussed in detail hereafter.

\section{Methodology}

This paper is developed based on a literature review covering FEWS since the year 2000 and information collected through a comprehensive global survey conducted to identify the operational effectiveness of FEWS $[9,41]$. The authors' past experiences in Mali, Niger, West Africa, and Sri Lanka [51-54,65] also enrich the analysis. To illustrate the role of CSOs in FEWS, we select case studies from the 'Views from the Frontline' (VFL) program of Global Network of CSOs for Disaster Reduction (GNDR) which encompasses countries such as Nigeria, India, Cameroon, Tonga, and Bangladesh. Moreover, we referred to several other studies from various countries conducted on this topic to bring meaningful examples and evidence on the social challenges of FEWS.

\subsection{The 'Views from the Frontline' (VFL) program}

The Global Network of CSOs for Disaster Reduction (GNDR) was launched at the Global Platform for Disaster Risk Reduction in Geneva to improve the lives of people affected by disasters worldwide in 2007 [38]. VFL [39] is GNDR's flagship program launched in 2009 involving nearly 200 partner organizations around the globe. It is the most

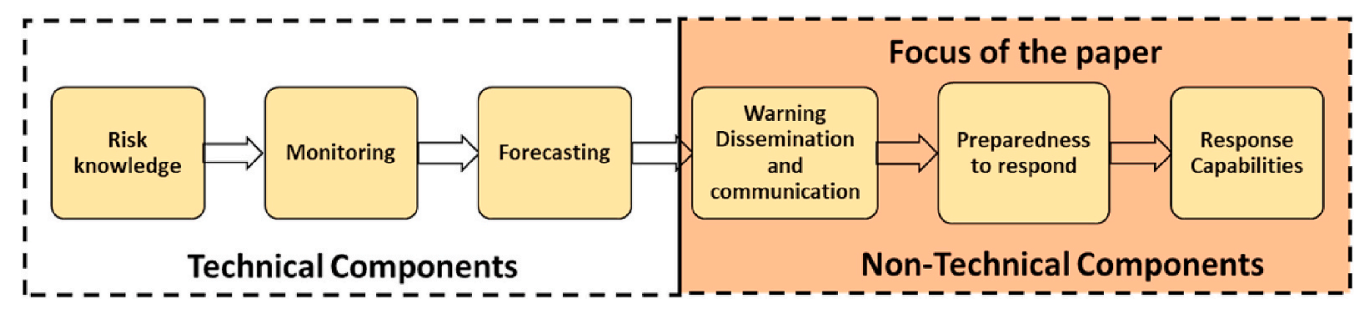

Fig. 2. Technical and Non-Technical Components of a Flood Early Warning System. 
extensive independent global review of DRR at the local level. It aims to strengthen the inclusion and collaboration among the people at-risk, civil society, and governments in the design and implementation of policies and practices to reduce risks and strengthen resilience. The VFL program has received nearly 100,000 survey responses, and CSOs appeared as "DRR champions" at the commune level in closing FEWS gaps.

\section{Results and discussion}

\subsection{Challenges in warning dissemination and communication}

The flaws in warning dissemination and communication can take place in different scales and can arise at any stage of a flood event. The following two disasters provides examples of how such flaws attribute to social challenges.

Event 1: A flash flood disaster in the Cameron Highlands, Malaysia occurred on October 23, 2013, when authorities had to make an emergency release from the Sultan Abou Bakar dam [55]. A siren was activated at the time of the release, but the same siren was used before for normal nonlife-threatening water releases. The warning was, therefore, not correctly interpreted, leading to casualties and loss of property. Post-disaster interviews showed that victims believe strongly that the flash flood early warning system was confusing and dysfunctional, and communities had failed to respond positively to it.

Event 2: Cyclone Eline was a category 4 hurricane that started on February 1, 2000, in the Indian ocean and hit Madagascar, Mozambique, Southern Africa, causing between 700 casualties and 500,000 homeless [56]. The effectiveness of the early warning system during Cyclone Eline was discussed by Gwimbi [56]. A post-disaster survey of 78 victims showed that only $11.6 \%$ of respondents received the warning before the floods; $14.1 \%$ during the flood only; $16.7 \%$ after the flood; $5.2 \%$ before, during and after floods and finally, 53.8\% during and after floods.

In technology-based FEWS, a "top-down approach" is usually used, where a national (or international) technical agency issues warnings and communicates them to the national authorities. The alerts are then channeled through to the regional, district, and local government authorities, disaster management agencies, CSOs involved to flood risk management. Media organizations such as newspapers, TV and local radio stations, security forces, and local police are contacted last and tasked to convey the warnings to the vulnerable population. Unfortunately, the warnings does not reach all the people-at-risk [10] equally and timely, particularly those in remote and/or coastal areas, illiterate and/or impoverished people, highly vulnerable groups such as women, children, and elderly in developing and least developed countries [9]. The reason is that warning messages are generally broadcasted on national or local media (television, radio, or website), and such vulnerable groups lack access to basic amenities required to receive these warnings [21]. The reasons for low access to the broadcasted messages include power outages, lack of access to TV and radio, limited signal for mobile phones during natural hazards, and limited knowledge of using the emergency websites for flood warnings and updates.

Even when the warning reaches a particular community, many fail to heed the warning because of to a lack of risk awareness, and doubts about the credibility of the warning [22,23]. It is possible to improve the credibility of the early warnings: for instance, the Cuban Institute of Meteorology was able to regain the trust of the people by using enhanced communication, improving forecast accuracy, and replacing TV broadcasters by trained meteorologists to communicate warning information [43].

To circumvent the limited access to media, alternative modes of communication such as sirens and loudspeakers can be used to reach low-income vulnerable people. However, this may result in delayed response since early warning passes through a chain of actors before reaching volunteer groups responsible for disseminating the alerts via megaphones and suchlike. By that time, evacuation routes may have become more dangerous for communities, specifically for women, children, and senior citizens. The involvement of well-prepared CSOs, the use of local communication pathways and available social media in the region can successfully bridge this gap in some cases. These particular groups are more likely to experience socio-economic, education and health-related constraints [24]. A study conducted in Nepal and Peru [25] suggests that women experience more difficulties during evacuations because of lower physical strength, inability to swim, lack of decision-making abilities, and other cultural and social constraints and stereotypes. Time lags in communicating flood warnings across borders are significantly higher for the most vulnerable communities [26]. It was found that three out of ten deaths caused by transboundary floods are due to late delivery of early warning [26] that leaves fewer opportunities to reduce flood risk impacts.

Even when they are delivered, warnings are often incomplete due to the lack of standardized nomenclature, protocols, and standards for issuing the warnings. This leads to inadequate, irrelevant or missing information [10,27]. Further, warnings are often perceived as confusing if they are issued by multiple institutions (technical agencies, local authorities, disaster managers, non-government organizations) unless the communication is done in a coordinated and responsible manner. Multiple sources of communication paths have to be encouraged to ensure various channels to reach the vulnerable communities. Unless otherwise coordinated properly, multiple sources of warning may lead to a lack of clarity and misinterpretation of the warnings [10]. To trigger a responsive action, warning needs to be tailored to the local communities' interests, needs, and values. This involves the use of local language and content that targets the understanding of the recipient and contains an appropriately tailored course of action. However, in a 'command and control' type of FEWS, most warnings are communicated to the entire population through media organizations, rather than tailored/targeted warnings generated for individual groups $[10,27,28]$. For example, key informant interviews in Pakistan suggest that let alone targeted warnings and engaging communities in formulating flood risk message, government officials' stated and unstated assumptions reveal that they played their part only by passing the information to lower revenue officials without actually knowing if the potential victims received the warning in time [21].

Targeted warnings are particularly important for uneducated people at flood risk in remote areas who cannot understand and act on generic warnings. For example, in a country where different languages exist at the national, state, and local-level, warning needs to be translated according to the target group at risk for them to heed warnings. Similarly, community-specific warnings are particularly important for gender inclusion in flood risk areas of developing countries, as the technical jargon in warnings messages and highly professional languages used by media organizations makes it difficult for illiterate women to understand. For example, focal group discussions in Pakistan revealed that uneducated women in certain Punjabi speaking communities were unable to comprehend the warning messages that included figures about millimeters of rainfall or percent probability of flooding and the formal Urdu language used by the TV [21].

An interactive and effective warning-communication chain is essential to a successful FEWS since multiple stakeholders are involved at all levels, and across sectors. However, there are often weak interpersonal and Inter-Agency relationships between producers and consumers of early warnings [11]. In most cases, there is a limited or inefficient coordination and, thus, ineffective communication between specialized agencies generating warnings and communicating authorities assigned to alert the public [10]. The lack of clarity in the roles played by each institution involved in the warning-communication chain is, in part, a consequence of the absence of formal dedicated institutional structures with authority to issue and communicate warnings to those at risk [27]. The problem is more pronounced in transboundary river basins. For instance, Zahmatkesh et al. [29] mentioned that the absence of an active network of communication and 
coordination between Canadian provinces and US states for transboundary watersheds is a major communication challenge. A similar gap was found in a study conducted of FEWS for the Bhotekoshi river along the China-Nepal border, Karnali river on Nepal-India border, and Brahmaputra river on India-Bangladesh border in Asia [30]. Also, the catastrophic flood that occurred in Mozambique in 2000 on the Limpopo River, which's headwater is in South Africa [45], and frequent floods in Somalia emanated from upstream catchments in Ethiopia [46] are African examples for transboundary flood warning communication gaps. All these gaps, in turn, weaken public interest and trust in FEWS resulting in fewer responses to flood alerts.

\subsection{Challenges in preparedness}

In a previous study, the authors found that a community's readiness to effectively respond upon receiving early warning is limited [9], which often stems from various inter-related challenges such as limited public interest and risk awareness, as well as inadequate involvement or encouragement of the government in preparing vulnerable communities [31]. The minimal public interest and engagement is often due to limited understanding about why community's prompt response is imperative, how their response affects reduction in humanitarian impacts, ambiguity in their roles in safeguarding their lives and livelihoods, irregular organizational awareness programs such as seminars, training, and drills to prepare the community before the natural disaster with contingency and disaster preparedness plans. The operationalization of awareness-raising seminars remains a challenge partly because of weak strategies in place. These include irregularity in awareness campaigns, training, and drills that may originate from the inadequate commitment of financial resources for risk mitigation and lack of understanding of DRR concept amongst key government stakeholders and local communities. For instance, in Indonesia, there was light coordination among government authorities, and no systematic strategy was in place for awareness-raising while in Macedonia, unsustainable commitment and capacities for such activities existed [31]. Therefore, there seems to be less impact of seminars on people's behavior during emergency response.

The participation of all at-risk residents in the decision-making process and the integration of traditional knowledge is vital to enhance the community's compliance with the flood warnings. However, there is limited awareness of including women as well as social groups such as ethnic, religious or gender minority, LGBTIQ (Lesbian, Gay, Bisexual, Transgender, Intersex and Queer) individuals in the decision-making process [32]. Such groups are particularly vulnerable [33], and are covered under Gender Equality and Social Inclusion (GESI). The common understanding of GESI in the context of DRR is weak among key ministries and departments dealing with Disaster Risk Management (DRM) [32]. Their exclusion or limited inclusion in preparedness activities, including in designing response plans, makes them feel disempowered, and thus, they lose interest, which results in lower response rates. The Asian Ministerial Conference for Disaster Risk Reduction - AMCDRR [33] analyzed the responses from 10 governments and 12 non-state agencies in Asia and found that gender is often seen as a women's issue and did not address concerns of other social groups.

Moreover, when addressing women's concerns, governments kept more emphasis on their vulnerabilities and servicing them during emergencies as victims of disaster rather than focusing on their capabilities and treating them as individual community members with roles to play during and after disasters. This contributes to limitations in exploring gender dynamics, the promotion of inequalities, genderrelated structural issues, and their impact on participation and leadership in preparedness activities for DRR. Progressive community feedback sessions to be conducted by key officials for the lessons learned from previous disasters and integration of such feedbacks in response strategies are very limited [10].

Contingency plans, most commonly prepared at the national level
[31], are often not customized to better adapt to the target communities and integrate traditional knowledge in emergency response plans due to lack of participatory approaches in the planning and development of warning response measures [10]. The problem is complemented by fewer than necessary updates of contingency plans (since risks change over time, especially in the era of climate change and rapid urbanization) owing to the technical and financial resource constraints. For example, UNDRR [31] indicated that international donors fund nearly $80 \%$ of the contingency plans in Mozambique. However, these donations are inconsistent; therefore, the availability of funds for updating contingency plans may be limited. Moreover, evidence-based contingency planning is imperative to support the Sendai Framework for DRR. It requires the application of scientific approaches using genetic and socio-economic data. But these data are not available in all flood-prone areas of the world, therefore limiting the availability and effective functioning of contingency plans in all parts of the world.

Although Ohara et al. [34] aimed to close this gap by developing a method for local communities to conduct contingency planning, the use of such methods is limited as its effectiveness in different flood-affected areas of the world is not verified. Even though contingency plans are available in many countries, they are seldom carried during emergencies $[11,31,47]$. The implementation of the planned activities is impeded by weak information dissemination capacities and weak coordination among the actors at all levels. This ultimately leads to a lack of public awareness about the hazard areas, warning codes, evacuation pathways, and locations. As an example, plans and programs exist in Mauritania but are not operationalized; in Indonesia, most plans were presented in theory but were never tested, simulated, or used for emergency response [31]. In Nepal, response plans were not implemented or updated [31]. Limited inclusion of disaster risk awareness in the school curriculum further poses a barrier to risk awareness among the public. The lack of implementation of emergency plans is also an issue in the developed world. For example, a study of coastal flooding in England and France [57], and an assessment of flood emergency plans in England and Wales, France, and the Netherlands [49] provide evidence that the actual practice of emergency plans is still a challenge even in the developed world. The problem is compounded among impoverished people and communities with low literacy rates who are disproportionately affected during floods [3]. Education about warning-response makes vulnerable people feel empowered by building confidence in the warning system, ultimately leading to higher response rates.

Limited Inter-Agency coordination and planning, as well as the absence of political commitment and will to encourage preparedness activities, due to political and institutional mindset of post-disaster relief instead of risk mitigation strategies, often constitute barriers to preparedness capacities among the key government stakeholders. Consequently, this results in limited financial and technical resource availability and adversely affects resource allocation capacity and response functions of authorities on time. This challenge is particularly acute in transboundary river basins that necessitate capacity building through multinational cooperation in terms of adequate evacuation planning, updating of such plans, timely resource availability, allocation of such resources, responsibilities among the agencies, and authorities across political borders. An example of such issues is the Koshi flood that occurred in 2008 in Nepal, where over 400 people died, and millions were displaced. Because of the absence of cross border DRR framework between India and Nepal, many victims of Bihar, India, crossed the borders to take shelters in Nepal. The inter-governmental coordination of such a response was very poor and resulted in an outbreak of epidemics as there was no safe drinking water supply [31]. Moreover, political conflicts can worsen the situations; for example, because of conflicted relationships with Turkey and Azerbaijan, cross-border DRR was found to be impossible in Armenia. In Pakistan, the geopolitical situation was such that it does not allow a free flow of information between other South Asian countries [31]. 


\subsection{Challenges in response capabilities}

Floods can be fast on-set disasters in small river basins while they can be slow on-set disasters for large river basins, especially in transboundary rivers. In all cases, timely response from the potential victims is critical to efficiently mitigating human, social, and economic losses. Despite that, several impediments are affecting the ability of target communities to respond when confronted with the early warning: risk perceptions, inefficient communication chain, limited options (resources) to respond, limited knowledge of evacuation routes, inadequate infrastructure and other facilitation for evacuees, risk of losing livelihood, properties, and livestock, a culture of neglect, and loss of trust in early warning systems. In some cases, it is not only the communities that don't have the information on evacuation actions and routes; often, those have not been assessed by the relevant authorities even in highincome countries such as the UK and France [57]. Affected residents often suffer from limited resources such as reliable modes of transportation, logistic support including life jackets, ropes, boat, helmet, stretcher, knowledge of feasible escape route options, and safe shelters to respond to the warnings $[11,30]$. For instance, in Dhubri and South Salmara districts located along the Brahmaputra river in India, sanitation facilities and clean drinking water supplies were not available to communities during floods [30]. Safe upstream shelters for flood victims were also found to be either inadequate or non-existent in some areas where FEWS are active. For example, only one emergency shelter platform was constructed for about twenty-two communities in the Dhubri district in India. In the absence of flood shelters, victims had to stay in the public schools with limited facilities, particularly in rural areas [30]. Due to limited viable escape routes and modes of transport, evacuees often find insufficient boats for transportation, poor roads condition, deteriorated infrastructures, limited public transport as a result of the flood, which are all essential for warning response [11,30,31].

Risk perception is another major challenge among flood-prone communities as it largely affects their attitudes about heeding the warnings [11]. Individuals at risk tend to relate their past experiences of warning response to the current flood scenarios, while each flood is unique due to changing threats in the wake of climate change. Therefore, the response plan and methods should also be updated in line with present flood scenarios. Further, relating past experiences and using indigenous knowledge such as observing animal behavior, changes in flora and fauna, observation of wind direction and the shape of a crescent moon, and astronomy may be helpful to cope with low magnitude flood events [60-64]. But for the rapid, high-intensity, frequent events that are experienced nowadays, the application of such knowledge was not found to be very effective [35]. Flood victims often lack such updated knowledge and fail to understand the situation and react accordingly. This is particularly true for high-risk groups such as women, children, and the elderly and people with low literacy levels in flood-prone communities. This may lead to a "culture of neglect" among the potential victims. For instance, Perera et al. [9] found that although warnings are often conveyed, only about half of the residents responded to the warnings amongst surveyed FEWS. Such a tendency to neglect warnings is common among many other FEWS [30,31], particularly in developing and least developing countries. However, such cases can be found in the developed world as well. A study conducted by Berry et al. [58] found that a significant number of flood causalities are associated with driving under extreme weather conditions, with victims ignoring the extended specific warnings for motorists. Gissing et al. [59] found that in $84 \%$ of studied cases, motorists have ignored issued warnings, and continued driving through floodwater. While there exists a culture of neglect everywhere, there also exists a culture of fatalism in some societies that leads to the acceptance of fatal effects of high-intensity disasters and weaken community responses. One such example is mentioned in Ref. [36], where potential victims were aware of the threat of an impending high magnitude disaster, but by fatalism did not evacuate while recognizing the seriousness of the situation. Eventually, victims inherently accept the flood risk rather than building resilience or work towards changing risks. This further hampers the ability of FEWS to reduce casualties. Because of the increasing use of social media and its role in spreading warning messages, there are higher chances of inaccurate or misleading warning information being disseminated on social media. As a consequence of the overflow of information from unofficial sources, communities tend to overreact, panic, become anxious, or get confused over responding to such messages [31], which can cause inconvenience to the public or lead to mixed responses delaying an effective response.

A prompt response is necessary for safeguarding lives, livestock, household necessities to higher grounds once the warning is conveyed. However, strong cultural ties to the ancestral land, risk of losing livelihood and assets pose as barriers to the ability of a community to respond to early warnings. People in some at-risk communities tend not to move to safer grounds as they are very attached to their ancestral land [31] or due to the risk of losing their properties as they do not possess property entitlement papers [21]. The safety of resident's assets is another concern as when assets are left unwatched, there is a higher potential of valuables being stolen. Moreover, securing livelihoods like livestock, farming equipment, physical property, and assets are also important in the view of delayed compensation from the governments and/or insurance. For instance, in the flood-affected district of Dhubri in India, the compensation verification process was in progress even after eight months after the disaster, and the promised amount was not provided to the needful [30]. The problem worsens in case of low-income and illiterate victims who are unaware of such rights. All these, in turn, either extends the response time increasing the vulnerability or affects response rates altogether.

\section{Role of Civil Society Organizations in addressing challenges}

According to UNDP [37], CSOs can be defined as all non-market and non-state organizations outside of the family in which people organize themselves to pursue shared interests in the public domain. Examples include community-based organizations and village associations, non-governmental organizations (NGOs), environmental groups, women's rights groups, farmers' associations, faith-based organizations, labor unions, co-operatives, professional associations, chambers of commerce, independent research institutes and the not-for-profit media." CSOs work with local communities and often substantiate the DRR efforts at the local level by instilling DRR knowledge, training, and practices. Exploring the role of CSOs in closing the social gaps identified in the previous section is imperative because they have a better understanding of the community's experiences, the impact of disasters on people-at-risk and serve as an important link between local government actors and at-risk residents. CSOs also appeared as "DRR champions" at commune level among other local actors in a global survey of 7000 people conducted by Global Network of Civil Society Organizations for Disaster Reduction [38]. GNDR was launched at Global Platform for Disaster Risk Reduction in Geneva, and it is the largest international network of organizations committed to working together to improve the lives of people affected by disasters worldwide [38]. GNDR's members implemented 'Views from the Frontline' program [39], which is the most extensive independent global review of DRR at the local level (96, 000 survey responses to date). It aims to bridge the gaps between policy formulation at the international level and realities of policy execution at the local level by strengthening the inclusion and collaboration between at-risk people, civil society, and governments in the design and implementation of policies and practice. Fig. 3 presents scores generated from the responses to a survey on community involvement by CSOs and local government in planning and implementation of policies, actions, and plans to mitigate disaster risks [39]. A level 1 score means no involvement at all while a level 5 score means a very effective community involvement. It is evident from the figure that most respondents (over $40 \%$ ) believe that there exists no community engagement by local 


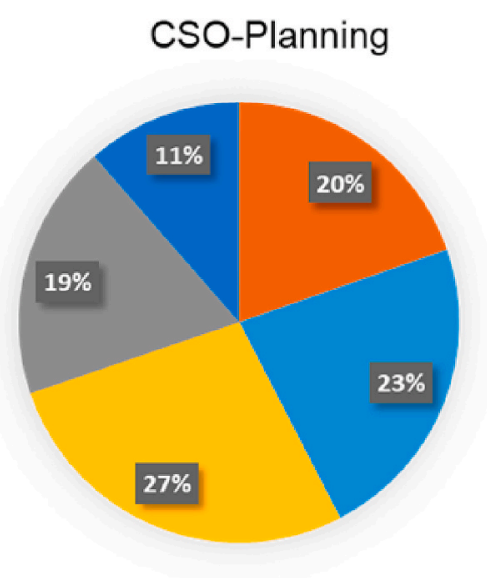

CSO-Implementation

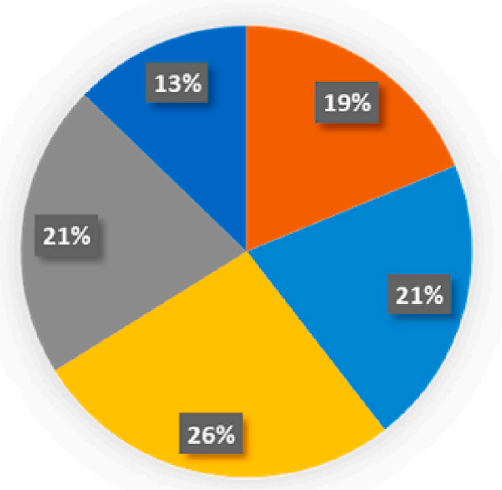

Local Government-Planning

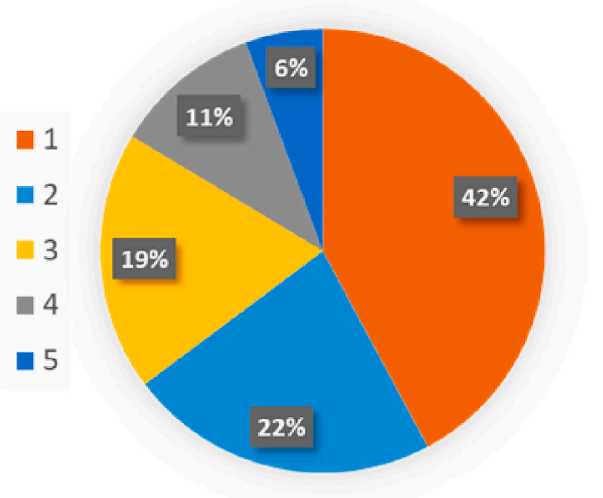

Local Government-Implementation

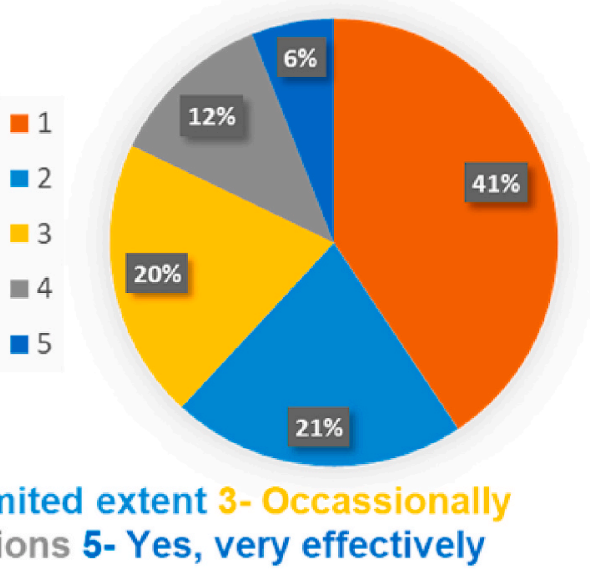

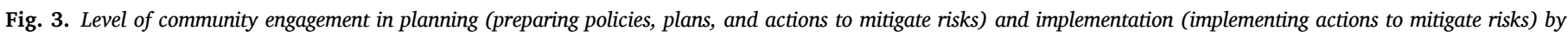

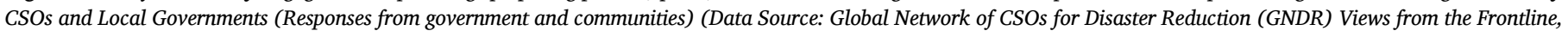
2019, https://vfl.world/explore-vfl-data/).

governments at all (scores at level 1). Most respondents (over a quarter) scored CSOs involvement at level 3, meaning they occasionally involve communities in planning and implementation. However, it is worth noting that responses for both the government and communities were provided by government officials, while CSOs provided their own scorecards. Overall, more than $60 \%$ of respondents perceive that governments do not involve communities at all or involve them to a very limited extent.

On the other hand, more than $60 \%$ of respondents believe that community engagement by CSOs is within scores 3 to 5 , i.e., occasional, with some limitations or is very effective. This initiative has resulted in the development of new local action plans, the establishment of new coalitions, and CSOs acting as national advocates and influencing the governments to change policies and plans to incorporate the review data. Some illustrations of their actions in addressing the previously mentioned social challenges are described hereafter.

Clarity of institutional roles and responsibilities and tailored contingency plans were found to be warning dissemination challenges described in the previous section. CSOs contributed to this sector in the most flood prone Gbekuba community in Ido, Nigeria, where actions were taken on the community's concerns about recurrent flood impacts and awareness of rights before, during, and after flood disasters [40]. The Centre for Disaster Risk and Crisis Reduction (CDRCR) organized meetings for communities and CSOs to design and implement a campaign in which impacting flyers were shared door-to-door, highlighting the steps to follow during, before, and after the emergencies. A rally was also held to draw the community's attention towards the responsibility of government departments that can help during disasters. Consequently, personal contingency plans were developed by at-risk communities. Local flood response teams were organized to provide information to the governments before the floods and relationships were built between different flood management actors. These actions empower communities to proactively protect themselves from floods and hence build resilience to disasters.

In order to turn policy into practice, Sustainable Environment and Ecological Development Society (SEEDS), a GNDR member, established a multi-stakeholder Citizen's Forum to bridge the gap between local government and communities and address local concerns relating DRR in the most vulnerable parts of East Delhi in India [40]. This forum has resulted in local government being more receptive to community needs and ensured joint action is taken by providing communities direct access to the local government authorities for voicing their concerns. This was achieved by creating community action groups that included high-risk groups such as women, children, and elderly and organizing capacity-building workshops so communities can identify local issues and act to reduce the risks their community faces. Capacity building seminars enhanced community involvement that led to an increased number of volunteers joining the effort and taking initiatives in tackling risks in their communities.

Communities engagement in decision making was also identified as one of the challenges in preparedness activities. GNDR attempted to address this gap by involving communities in decision making and focusing on their priorities and needs to take local evidence-based collaborative action. For example, the NGO, Geotechnology, 
Environmental Assessment, and Disaster Risk Reduction (GEADIRR) found through a local survey that recurrent flooding in every rainy season in the Lower Motowoh region of Cameroon was caused by garbage that blocked the river flow [40]. The NGO led the discussion of follow-up actions involving the communities and local authorities and came to a collaborative solution to which all the stakeholders contributed. The watercourse was then cleared by dredging the rubbish for faster water flow, which led to the prevention of floods in the rainy season the next year. Such collaborative actions are more effective and treat the root cause of the problem making local actions sustainable.

Key government stakeholder's mindset of post-disaster relief instead of disaster risk mitigation was also found as a preparedness challenge. CDRCR in Nigeria recognized negligent attitudes of government officials responsible for implementing global frameworks, including the Sendai Framework. Therefore, an advocacy initiative was hosted for changing attitudes of key government stakeholders targeting the government Ministries, Departments, and Agencies (MDAs) directly working for disaster risk management in the country. This included stressing on the importance of effective implementation of Sendai Framework for at-risk communities and the development and delivery of a simplified version of Sendai Targets and priorities for action to facilitate the understanding of public officials. Such an initiative has led to several positive actions taken at the state level, including the development of implementation plans for the Sendai Framework, providing a budget for disaster resilience activities, and establishing functional local emergency management authorities within the states. Overall, the advocacy campaign improvised understanding of the targeted roles of each level of government in implementing DRR and led to positive attitudes and will to implement global frameworks.

One other challenge mentioned previously was the limited inclusion of women, in general, in the DRR activities. Frontline, through representative surveys, including women, found that women and girls are most vulnerable to disasters in Tonga. NGOs realized that women could influence their families and society as a whole. Therefore, Tonga Community Development Trust hosted a workshop focusing on women and girls discussing the disasters and ways to mitigate their impacts [40]. It also emphasized the importance of diversity and inclusiveness of the entire community in DRR. Discussions also took place on the alternative livelihoods, and participants were trained on making some popular tourist items. Since livelihood is an important subject among many communities in developing countries, this step can lead to long term engagement of women in such DRR activities. All this resulted in empowering women, engaging them, and imparting a better understanding of disasters and measures to build resilience against it in their families and thus communities.

Even though CSOs have been active in DRR efforts, it should be noted that they exist only in some flood-affected parts of the world. Take the cross-border Brahmaputra river in India and Bangladesh, for example, where the districts along the shoreline experience recurrent riverine and flash floods, but no NGOs or any other influential CSOs are working in these flood-prone districts neither in India nor in Bangladesh [30]. This can be because CSOs have their limitation in terms of unsustainable funding to carry out macro scale as well as micro-scale projects in different countries.

\section{Conclusions and Recommendations}

The study used evidence from a survey and published literature to identify and discuss gaps in communication, preparedness, and response stages to warnings issued by FEWS. The survey conducted by the authors [9] and other studies cited in this paper suggest that in the communication component, warnings, even when issued and disseminated with enough lead time, do not necessarily reach all the people-at-risk. When the warnings reach communities, too many people fail to heed them. Warning messages are often either incomplete, in a different language, or too technical for potential victims to understand. Very often, the messages are not tailored to the need of the community and not formulated for easy uptake by highly vulnerable groups. Coordination and communication between different actors of early warning systems for communicating warnings were found to be lacking particularly for transboundary river basins.

The challenges identified about the preparedness component of FEWS include the lack of public interest and risk awareness in early warnings; limited and irregular drills and training seminars; general contingency planning instead of specific and tailored to the community; absence of political commitment and will; financial and technical resource constraints for DRR; minimum participation of communities in the decision-making process; and lack of Inter-Agency planning and coordination, particularly among transboundary river basins. High-risk groups, including women, indigenous people, ethnic and religious minorities, elderly, children, disabled individuals in remote and isolated areas generally suffer even more exclusion [33]. In the response capabilities component of FEWS, identified gaps include insufficient upstream shelters and other resources to respond; wrong risk perceptions despite changing flood regimes; a culture of neglect; and a lack of trust in authorities.

Overall, some of the emerging cross-cutting issues were inadequate participatory approaches through community involvement and addressing their concerns in warning, preparedness and response stages of FEWS; inadequacy in translating DRR policies and frameworks into action at commune level; limited DRR knowledge in communities as well as key stakeholders; inadequate inclusion of diversity in terms of GESI in all the stages of FEWS; ineffective Inter-Agency and multinational communication and collaboration and unsustainable technical and financial resource availability for DRR. However, there are ongoing interventions to address these issues, including by CSOs that play an important role between the communities' and key government stakeholders. Some of the ways the Global Network of CSOs for Disaster Reduction (GNDR) has addressed these challenges include tailored solutions to community-specific concerns; DRR awareness and education to communities and key officials; enhanced communication between people-at-risk and local authorities; creation of proactive response and action by empowering and involving the communities; implementation of GESI at various stages of FEWS development; and conducting advocacy campaigns to build resilience against disasters.

Translating flood early warnings into a rapid, responsive action by every individual at risk of flood disaster and in all the flood-affected areas around the world requires coordinated and collaborative action from all the actors and stakeholders of early warning at all levels. To achieve a significant reduction in flood disaster-related risks, and build resilience in all the communities affected by floods in line with Sendai targets for DRR, the following recommendations are put forward:

\section{a. Warning Dissemination and Communication}

- Expand the coverage of information and communication infrastructure so that warning can reach remote locations in developing and least developed countries.

- Tailor the warning messages in local community languages in a simplified manner.

\section{(E.g. Cases of Pakistan [21] and Uganda [27]).}

- Establish a clear two-way communication of updated emergency preparedness plans, organizational structure, and institutional responsibilities across government, disaster management organizations, and communities-at-risk. (E.g. The case of Cuba [43] shows that more transparent communication improves the level of awareness and response)

- Involve well-prepared CSOs in the warning communication process (From the case from Nepal [24], ease the community unrest in understanding the warning) 
- Increase the awareness of FEWS operators and designers about nontechnical and social aspects of FEWS and invest more resources on these aspects.

b. Preparedness

- Increase the local outreach and development of healthy understanding among the stakeholders, community engagement through improved strategical communications channels, and transformation of DRR policies into action on real ground.

(E.g. the cases found in Indonesia and Macedonia [31], the limited involvement from government authorities and ineffective strategies in disaster drills and capacity building programs minimize the communities' interest in preparedness).

- Implement funding-related policies to encourage local level flood risk mitigation by funding CSOs' networks and community volunteers towards gender integration and social inclusiveness to improve preparedness.

c. Response Capabilities

- Develop effective and efficient working relationships between flood warning issuing agencies and ground-level disaster managers and foster the effective communication among the stakeholders to improve the trust of issued warning and consequently improve the response levels of vulnerable communities.

- Improve local outreach and community engagement through better media, communication, and DRR policies to ensure community response and prompt actions when a disaster occurs and transform them into action.

\section{Declaration of competing interest}

The authors declare that they have no known competing financial interests or personal relationships that could have appeared to influence the work reported in this paper.

\section{Acknowledgments}

This research is supported by the funds received by UNU-INWEH through the long-term agreement with Global Affairs Canada. Thanks are due to Dr. Vladimir Smakhtin (UNU-INWEH) for the constructive comments on the paper. The authors are thankful to the anonymous reviewers who helped improve the manuscript.

\section{Appendix A. Supplementary data}

Supplementary data to this article can be found online at https://doi. org/10.1016/j.ijdrr.2020.101794.

\section{References}

[1] EM-DAT, CRED, EM-DAT, The Emergency Events Database, Univ. Cathol. Louvain CRED, Brussels, Belgium, 2019. www.emdat.be. (Accessed 2 October 2019).

[2] UNDRR, Report of the open-ended intergovernmental expert working group on indicators and terminology relating to disaster risk reduction, United Nations General Assembly. Agenda Item (C) (2017) 19. https://www.preventionweb.ne t/files/50683_oiewgreportenglish.pdf.

[3] R. Basher, J. Page, J. Woo, M.L. Davies, C.E. Synolakis, A.F. Farnsworth, S. Steacey, Global early warning systems for natural hazards: systematic and people-centred, Philos. Trans. R. Soc. A Math. Phys. Eng. Sci. (2006), https://doi.org/10.1098/ rsta.2006.1819.

[4] J. Cools, D. Innocenti, S. O'Brien, Lessons from flood early warning systems, Environ. Sci. Pol. (2016), https://doi.org/10.1016/j.envsci.2016.01.006.

[5] F. Pappenberger, H.L. Cloke, D.J. Parker, F. Wetterhall, D.S. Richardson, J. Thielen, The monetary benefit of early flood warnings in Europe, Environ. Sci. Pol. (2015), https://doi.org/10.1016/j.envsci.2015.04.016.

[6] J. Thielen-del Pozo, V. Thiemig, F. Pappenberger, B. Revilla-Romero, P. Salamon, T. DeGroeve, F. Hirpa, The Benefit of Continental Flood Early Warning Systems to Reduce the Impact of Flood Disasters, 2015, https://doi.org/10.2788/46941.

[7] UNDRR, Early Warning as a Matter of Policy, Bonn, Germany, 2004. https://www. unisdr.org/files/8290_earlywarningasamatterofpolicy.pdf.
[8] WMO, Flood Forecasting and Early Warning, World Meteorol. Organ., 2013, pp. 1-84. https://library.wmo.int/doc_num.php?explnum id=4269.

[9] D. Perera, O. Seidou, J. Agnihotri, M. Rasmy, V. Smakhtin, P. Coulibaly, H. Mehmood, Flood Early Warning Systems: A Review of Benefits, Challenges and Prospects, Canada, Hamilton, 2019. http://inweh.unu.edu/publications/.

[10] UN, Global Survey of Early Warning Systems, An Assessment of Capacities, Gaps and Opportunities toward Building a Comprehensive Global Early Warning System for All Natural Hazards, 2006.

[11] IFRC, World Disaster Report: Focus on Early Warning, Early Action, 2009. http://www.ifrc.org.

[12] UNDRR, Revealing Risk, Redefining Development, 2011. http://www.preventionw eb.net/english/hyogo/gar/2011/en/bgdocs/GAR-2011/GAR2011_Report_Prelims. pdf.

[13] UNEP, Early Warning Systems A State of the Art Analysis and Future Directions, 2012, https://doi.org/10.1016/j.envdev.2012.09.004. Nairobi.

[14] UNDRR, Making Development Sustainable, The Future of Disaster Risk Management, Global Assessment Report on Disaster Risk Reduction., Geneva, Switzerland, 2015.

[15] L. Alfieri, P. Salamon, F. Pappenberger, F. Wetterhall, J. Thielen, Operational early warning systems for water-related hazards in Europe, Environ. Sci. Pol. (2012), https://doi.org/10.1016/j.envsci.2012.01.008.

[16] F. Hossain, A.H.M. Siddique-E-Akbor, W. Yigzaw, S. Shah-Newaz, M. Hossain, L. C. Mazumder, T. Ahmed, C.K. Shum, H. Lee, S. Biancamaria, F.J. Turk, A. Limaye, Crossing the "valley of Death": lessons learned from implementing an operational satellite-based flood forecasting system, Bull. Am. Meteorol. Soc. (2014), https:// doi.org/10.1175/BAMS-D-13-00176.1.

[17] V.V. Krzhizhanovskaya, G.S. Shirshov, N.B. Melnikova, R.G. Belleman, F.I. Rusadi, B.J. Broekhuijsen, B.P. Gouldby, J. Lhomme, B. Balis, M. Bubak, A.L. Pyayt, I. I. Mokhov, A.V. Ozhigin, B. Lang, R.J. Meijer, Flood early warning system: design, implementation and computational modules, in: Procedia Comput. Sci., 2011, https://doi.org/10.1016/j.procs.2011.04.012.

[18] P.J. Smith, F. Pappenberger, F. Wetterhall, J. Thielen Del Pozo, B. Krzeminski, P. Salamon, D. Muraro, M. Kalas, C. Baugh, On the operational implementation of the European flood awareness system (EFAS), flood forecast, Global Perspect. (2016) 313-348, https://doi.org/10.1016/B978-0-12-801884-2.00011-6.

[19] V. Thiemig, A. de Roo, H. Gadain, Current status on flood forecasting and early warning in Africa, Int. J. River Basin Manag. (2011), https://doi.org/10.1080/ 15715124.2011.555082.

[20] J. Cools, P. Vanderkimpen, G. El Afandi, A. Abdelkhalek, S. Fockedey, M. El Sammany, G. Abdallah, M. El Bihery, W. Bauwens, M. Huygens, An early warning system for flash floods in hyper-arid Egypt, Nat. Hazards Earth Syst. Sci. (2012), https://doi.org/10.5194/nhess-12-443-2012.

[21] D. Mustafa, G. Gioli, S. Qazi, R. Waraich, A. Rehman, R. Zahoor, Gendering flood early warning systems: the case of Pakistan, Environ. Hazards (2015), https://doi. org/10.1080/17477891.2015.1075859.

[22] O.H. Amach, Early Warning Systems and "The Last Metre, " UNDRR, 2019. https:// www.unisdr.org/archive/64725. (Accessed 9 October 2019).

[23] J. Fowler, Bridging the "Last Mile" in Risk Awareness, UNDRR, 2016. https:// www.unisdr.org/archive/51301. (Accessed 9 October 2019).

[24] D.K. Gautam, A.G. Phaiju, Community based approach to flood early warning in west rapti river basin of Nepal, J. Integr. Disaster Risk Manag (2013), https://doi. org/10.5595/idrim.2013.0060.

[25] A. Sneddon, Reaching the Last Mile: Challenges and Lessons from Early Warning Systems, Pract. Action, 2018. https://practicalaction.org/news-media/2018/07/ 11/reaching-the-last-mile-challenges-and-lessons-from-early-warning-systems/. (Accessed 4 November 2019).

[26] AIDMI, Trans-Boundary Early Warning Systems in Asia, Southasiadisasters.Net, Issue No. 180, All India Disaster Mitigation Institute (AIDMI), 2019.

[27] D. Lumbroso, How can policy makers in sub-Saharan Africa make early warning systems more effective? The case of Uganda, Int. J. Disaster Risk Reduct. (2018), https://doi.org/10.1016/j.ijdrr.2017.11.017.

[28] I. Stanciugelu, A. Bilanici, I. Cameron, Last mile communication, in: Commun. Disaster Risk, 2015.

[29] Z. Zahmatkesh, S. Kumar Jha, P. Coulibaly, T. Stadnyk, An overview of river flood forecasting procedures in Canadian watersheds, Can. Water Resour. J. (2019), https://doi.org/10.1080/07011784.2019.1601598.

[30] M. Rahman, G.B. Gurung, G.P. Ghimire, Trans-border Flood Early Warning System in South Asia: Practices, Challenges and Prospect, Practical Action, Kathmandu, Nepal, 2018.

[31] UNDRR, Progress and Challenges in Disaster Risk Reduction: A Contribution towards the Development of Policy Indicators for the Post-2015 Framework on Disaster Risk Reduction, United Nations Off. Disaster Risk Reduct, 2014.

[32] AMCDRR, Progress Review and the Way Forward: Gender Equality and Social Inclusion in Implementing the Sendai Framework for Disaster Risk Reduction in Asia, 2018. https://asiapacific.unwomen. org/en/digital-library/publications/2018/12/progress-review-and-th e-way-forward\#view.

[33] S. Aryal, Gender and Social Inclusion for Implementing the Sendai Framework in the Asia Regional Plan 2016-2018: A Review of Progress and Way Forward, AMCDRR, 2018. https://www.preventionweb.net/files/56219_3th04thematicsessi ongenderregionalg.pdf.

[34] M. Ohara, N. Naoko, B.B. Shrestha, H. Sawano, Evidence-based contingency planning to enhance local resilience to flood disasters, Recent Adv. Flood Risk Manag. (2018). 
[35] E. Mavhura, S.B. Manyena, A.E. Collins, D. Manatsa, Indigenous knowledge, coping strategies and resilience to floods in Muzarabani, Zimbabwe, Int. J. Disaster Risk Reduct (2013), https://doi.org/10.1016/j.ijdrr.2013.07.001.

[36] E. Romo-Murphy, M. Vos, The Role of Broadcast Media in Disaster Preparedness Education: Lessons Learned in the Scientific Literature 2002-2012, Media Asia, 2014, https://doi.org/10.1080/01296612.2014.11690001.

[37] UNDP, Working with Civil Society in Foreign Aid. Possibilites for South-South Cooperation?, China, 2013.

[38] GNDR, Views from the Frontline, 2009. https://www.gndr.org. London, UK.

[39] GNDR, Views from the Frontline, 2019. https://vfl.world/explore-vfl-data/. (Accessed 4 December 2019).

[40] GNDR, Local Voices for Resilience, London, UK, 2018.

[41] https://inweh.unu.edu/questionnaire-evaluation-of-flood-early-warning-systems/.

[42] D.M. Lumbroso, N.R. Suckall, R.J. Nicholls, K.D. White, Enhancing resilience to coastal flooding from severe storms in the USA: international lessons, Nat. Hazards Earth Syst. Sci. 17 (2017) 1357-1373, https://doi.org/10.5194/nhess-17-13572017.

[43] D. Lumbroso, J. Rance, G. Pearce, E. Brown, S. Wade, Science for Humanitarian Emergencies and Resilience (SHEAR) Scoping Study: Annex 2 - the Current Status of Early Warning Systems and Risk Assessments in Africa, the Caribbean and South Asia - A Literature Review, 2014, https://doi.org/10.12774/eod_cr.june2014. lumbrosorance.

[44] M.S. Hossain, Flood forecasting and warning in Bangladesh | world meteorological organization, World Meteorol. Organ. Bull. 67 (2018). https://public.wmo.int/en/ resources/bulletin/flood-forecasting-and-warning-bangladesh. (Accessed 1 July 2020).

[45] D. Mayers, Early Flood Warning Save Lives in Mozambique, ZDnet, 2013. https:// www.zdnet.com/article/early-flood-warnings-save-lives-in-mozambique/.

[46] Somalia ReliefWeb, Flash Floods, 2020. https://reliefweb.int/disaster/ff-2020 -000055-som. (Accessed 1 July 2020).

[47] L. Clarke, Mission Improbable: Using Fantasy Documents to Tame Disaster, 1999.

[48] Asian Disaster Preparedness Center, ADPC: Building Flood Preparedness in Community: Implementing Early Warning Systems in Ayutthaya, Thailand, 2015 https://www.adpc.net/igo/contents/Publications/publications-Details.asp? pid=1061. (Accessed 1 July 2020).

[49] D. Lumbroso, E. Brown, N. Ranger, Stakeholders' perceptions of the overall effectiveness of early warning systems and risk assessments for weather-related hazards in Africa, the Caribbean and South Asia, Nat. Hazards 84 (2016) 2121-2144, https://doi.org/10.1007/s11069-016-2537-0.

[50] ICIMOD, Community-based Flood Early Warning System, The Story from Then to Now, 2018. http://www.unisdr.org/2006/ppew/whats-ew/basics-ew.htm. (Accessed 1 July 2020).

[51] O. Seidou, F. Alher, Mise en place d'un système opérationnel d'alerte précoce aux inondations pour la ville de Gaya et la commune de Tanda. Technical report, Ministère de l'Action Humanitaire et de la Gestion des Catastrophes/PNUD Niger, 2019, p. 118.

[52] O. Seidou, Mise en place d'un système opérationnel d'alerte précoce aux inondations au Mali, Technical report, Agence pour l'Environnement et de Développement Durable/PNUD Mali, 2019, p. 82.
[53] S. Kheradmand, O. Seidou, D. Konte, M.B. Barmou Batoure, Evaluation of adaptation options to flood risk in a probabilistic framework, J. Hydrol. Reg. Stud. 19 (2018) 1-16, https://doi.org/10.1016/j.ejrh.2018.07.001.

[54] S. Kokularamanan, A.W. Rasmy, D. Perera, T. Koike, Development of a flood forecasting and data dissemination system for kalu river basin in Sri Lanka, Annu. Sess. IESL, Inst. Eng. Sri Lanka (2017) 205-210.

[55] M.S. Khalid, C.S. Mustaffa, M.N. Marzuki, M.F. Sakdan, S. Sipon, M.T. Ariffin, S. Shafiai, Failure to react positively to flood early warning systems: lessons learned by flood victims from flash flood disasters: the Malaysia experience, Int Sch. Sci. Res. Innov. 9 (2015) 9-14, https://doi.org/10.5281/ZENODO.1100585.

[56] P. Gwimbi, The effectiveness of early warning ststems for the reduction of flood disasters: some experiences from cuclone induced floods in Zimbabwe, J. Sustain. Dev. Afr. 9 (2007) 152-169. http://www.jsd-africa.com/Jsda/V9n4_Winter2007/ PDF/EfectivenessEalierWarningSystem.pdf. (Accessed 1 July 2020).

[57] D. Lumbroso, F. Vinet, Tools to improve the production of emergency plans for floods: are they being used by the people that need them? J. Contingencies Crisis Manag. 20 (2012) 149-165, https://doi.org/10.1111/j.1468-5973.2012.00665.x.

[58] L. Anderson-Berry, T. Achilles, S.P.-I. journal of, undefined, Sending a Message: How Significant Events Have Influenced the Warnings Landscape in Australia, Elsevier, 2018 n.d. https://www.sciencedirect.com/science/article/pii/S2212420 918302760. (Accessed 1 July 2020).

[59] A. Gissing, K. Haynes, L. Coates, C. Keys, Motorist behaviour during the 2015 Shoalhaven floods, Aust. J. Emerg. Manag. 31 (2016) 25-30. www.floodsafe.com. au. (Accessed 1 July 2020).

[60] M. Kalanda-Joshua, C. Ngongondo, L. Chipeta, F. Mpembeka, Integrating indigenous knowledge with conventional science: enhancing localised climate and weather forecasts in Nessa, Mulanje, Malawi, Phys. Chem. Earth 36 (2011) 996-1003, https://doi.org/10.1016/j.pce.2011.08.001.

[61] R. Kangalawe, S. Mwakalila, P. Masolwa, Climate change impacts, local knowledge and coping strategies in the great ruaha river catchment area, Tanzania, Nat. Resour. 2 (2011) 212-223, https://doi.org/10.4236/nr.2011.24027.

[62] A. Kijazi, L. Chang'a, E. Liwenga, A. Kanemba, The Use of Indigenous Knowledge in Weather and Climate Prediction in Mahenge and Ismani Wards, Tanzania, 2013. http://www.taccire.suanet.ac.tz:8080/xmlui/handle/123456789/197. (Accessed 1 July 2020).

[63] E. Charles Nkomwa, M. Kalanda Joshua, C. Ngongondo, M. Monjerezi, F. Chipungu, Assessing Indigenous Knowledge Systems and Climate Change Adaptation Strategies in Agriculture: A Case Study of Chagaka Village, Chikhwawa, Southern Malawi, Elsevier, 2014, https://doi.org/10.1016/j.pce.2013.10.002.

[64] A. Nyong, F. Adesina, B. Osman Elasha, The value of indigenous knowledge in climate change mitigation and adaptation strategies in the African Sahel, Mitig. Adapt. Strategies Glob. Change 12 (2007) 787-797, https://doi.org/10.1007/ s11027-007-9099-0.

[65] SAFE, Developing and Implementing an Operational Prototype for Advanced Flood Forecasting, Early Warning, and Data Sharing System in the Kalu Ganga Basin, Sri Lanka, Dep. Irrig. -Sri Lanka, 2015. https://www.eorc.jaxa.jp/SAFE/prototyping/li neup/lka/201512/index.html. (Accessed 1 July 2020). 